Recepción: 17 / 06 / 2018

Aceptación: 14 / 08 / 2018

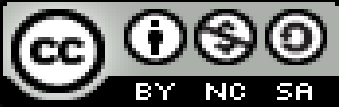

Publicación: 05 / 10 / 2018

\title{
La contraloría general del estado y su impacto en el control de los recursos
}

\section{Estatales}

The comptroller general of the state and its impact on the control of state resources

O comprolador geral do estado e seu impacto no controle dos recursos estatais

\author{
Rosa B. Calle-Oleas ${ }^{\mathrm{I}}$ \\ rosa.calle@unl.edu.ec \\ Audverto de J. Cueva-Cueva ${ }^{\text {II }}$ \\ audverto.cueva@unl.edu.ec
}

Correspondencia: rosa.calle@unl.edu.ec

\begin{abstract}
I Magister en Docencia Universitaria e Investigación Educativa, Magister en Gerencia Contable y Financiera, Doctora en Contabilidad y Auditoría, Docente de la Universidad Nacional de Loja, Loja, Ecuador.

II Doctor en Contabilidad y Auditoría, Licenciado en Contabilidad y Auditoría-Contador Público-Auditor, Magister En Docencia Universitaria e Investigación Educativa, Docente de la Universidad Nacional de Loja, Loja, Ecuador.
\end{abstract}




\section{Resumen}

La Contraloría General del Estado (CGE), de la República del Ecuador, tiene como misión controlar los recursos públicos en beneficio de la sociedad, además de tener como objetivos estratégicos: mejorar la comunicación e información entre la sociedad y la Contraloría General del Estado, actuar de forma efectiva en el control de los recursos públicos, desarrollar las competencias, desempeño y bienestar laboral del talento humano y fortalecer la capacidad de gestión y recursos institucionales.

La investigación aborda un análisis desde la perspectiva del control de los recursos públicos a cargo de la CGE para determinar diferentes tipos de responsabilidades de sus directivos al frente de una entidad gubernamental en particular. Se presenta un cuadro cronológico donde se muestran las etapas, denominación y acción de la Contraloría a través de su historia. Se presentan conceptos básicos de recursos de estado y control y finalmente se presenta un cuadro de predeterminación de responsabilidades donde se determina el monto que implica el incumplimiento de cada una de las unidades adscritas al organismo en mención (CGE), por inobservar las disposiciones establecidas en las normas. Se propone emplear de manera oportuna los entes encargados para reducir los casos de corrupción asociados al empleo de la influencia de altos cargos en la CGE.

Palabras clave: análisis; control; recursos públicos; responsabilidades.

\section{Abstract}

The Comptroller General of the State (CGE), of the Republic of Ecuador, has the mission of controlling public resources for the benefit of society, in addition to having as strategic objectives: improve communication and information between society and the General Comptroller of the State, Act effectively in the control of public resources, develop the skills, performance and work well-being of human talent and strengthen the management capacity and institutional resources. The research addresses an analysis from the perspective of the control of public resources by the CGE to determine different types of responsibilities of its managers in front of a particular government entity. A chronological chart is presented showing the stages, denomination and action of the Comptroller through its history. Basic concepts of resources of state and control are presented and finally a predetermination table of responsibilities is presented 
where the amount that implies the non-compliance of each of the units assigned to the mentioned body (CGE) is determined, by not observing the dispositions established in the rules. It is proposed to use in a timely manner the entities in charge to reduce the cases of corruption associated with the use of the influence of senior officials in the CGE.

Key words: analysis; control; public resources; responsibilities.

\section{Resumo}

A Controladoria Geral do Estado (CGE), da República do Equador, tem a missão de controlar os recursos públicos em benefício da sociedade, além de ter como objetivos estratégicos: melhorar a comunicação e a informação entre a sociedade e a Controladoria Geral do Estado, atuar efetivamente no controle de recursos públicos, desenvolver habilidades, desempenho e trabalhar o bem-estar do talento humano e fortalecer a capacidade de gestão e os recursos institucionais. A pesquisa aborda uma análise sob a perspectiva do controle de recursos públicos pela CGE para determinar diferentes tipos de responsabilidades de seus gerentes perante uma entidade governamental em particular. Um gráfico cronológico é apresentado mostrando as etapas, denominação e ação do Comptroller através de sua história. São apresentados conceitos básicos de recursos de estado e controle e, finalmente, é apresentada uma tabela de responsabilidades predeterminadas onde é determinado o montante que implica o descumprimento de cada uma das unidades atribuídas ao referido órgão (CGE), ao não observar as disposições estabelecidas no as normas. Propõe-se a utilização atempada das entidades encarregadas de reduzir os casos de corrupção associados ao uso da influência de altos funcionários na CGE.

Palavras chave: análise; controle; recursos públicos; responsabilidades.

\section{Introducción}

Desde tiempos de la colonia, el Ecuador, a través de sus diferentes administraciones gubernamentales ha requerido de la existencia de un organismo competente que se encargue de velar por el buen uso de los recursos púbicos en todas sus dimensiones, toda vez que es conocido que con esos recursos es que se puede servir a la colectividad en todas sus problemáticas sociales; por lo tanto, la eficacia en su manejo está reflejada en la maximización de los bienes y en el tiempo que han permanecido al servicio de una institución. 
Específicamente se aborda un análisis de las cantidades y montos (valores) de las responsabilidades establecidas en el año 2017, así como las principales entidades de dominio público que son controladas, sirviendo para desarrollar nuevas investigaciones en los campos legales y de los controles administrativos. Al finalizar el trabajo se expresa de manera clara como influye el control de los recursos públicos contra funcionarios corruptos y el empleo de estos recursos en forma oportuna.

\section{Metodología}

Para Martínez, S (2002) en su guía de apuntes básicos para el docente en materia de técnicas de investigación, disponible en: http://www.geiuma-oax.net/asesoriasam, consultado el 13 de febrero de 2017 la investigación es de tipo documental ya que los datos reflejados en la investigación son recopilados de los informes que son presentados por la CGE pero que son necesarios analizarlos con otras información teóricas para concluir si la labor de la organización es la más adecuada al frente del control optimo que se debe observar por parte de la entidades del sector estatal. También cumple con un proceso ordenado y lógico con suficiente información documental.

Identifica de manera preliminar fuentes documentales con el propósito de aproximarse al tema y finalmente desarrolla la difusión y comunicación de sus conclusiones.

\section{Revisión Bibliográfica}

\section{Contraloría General del Estado}

La CGE es definida en la Constitución Política de la República del Ecuador CPRE (Asamblea Nacional Constituyente, 2008) la misma que en su artículo 211 señala lo siguiente: La Contraloría General del Estado es el organismo técnico superior de control, con autonomía administrativa, presupuestaria y financiera, dirigido y representado por el Contralor General del Estado, quien desempeñará sus funciones durante cuatro años; adicionalmente señala que: Tendrá atribuciones para controlar ingresos, gastos, inversión, utilización de recursos, administración y custodia de bienes públicos. Realizará auditorías de gestión a las entidades y organismos del sector público y sus servidores, y se pronunciará sobre la legalidad, transparencia y eficiencia de los resultados institucionales. Su acción se extenderá a las entidades de derecho privado, 
exclusivamente respecto de los bienes, rentas u otras subvenciones de carácter público de que dispongan.

Estas definiciones son claras del alcance que tiene la entidad del estado para garantizar que los recursos del estado estén manejados de manera eficiente al servicio de toda la población, y en caso de presentarse o evidenciarse alteraciones, aplicar las sanciones establecidas para cada específico. En la medida del uso adecuado de los bienes y tributos que son administrados por distintas entidades como el Servicio de Rentas Internas, Aduana, Municipios, entre otros; es que una nación puede alcanzar su progreso que se ve reflejado en una mejor calidad de vida de los mandantes.

En el mismo documento CPRE constan los requisitos que se necesitan para ser Contralor, siendo los siguientes:

Ser ecuatoriano de Nacimiento

Hallarse en ejercicio de los derechos políticos

Tener título de profesión universitaria

Haber ejercido con prolijidad notoria la profesión o la catedra universitaria por un lapso mínimo 15 años, $\mathrm{y}$

Cumplir con los demás requisitos de idoneidad que fije la ley

\section{Historia de la CGE}

La Dirección de Tecnología de Información y comunicaciones (2016), Contraloría General del Estado. Recuperado de http://www.contraloria.gob.ec/consta la siguiente información disponible:

\begin{tabular}{|l|l|}
\hline \multicolumn{1}{|c|}{ ETAPAS } & \multicolumn{1}{|c|}{ DENOMINACIÓN - ACCIÓN } \\
\hline Real Audiencia de Quito & $\begin{array}{l}\text { Siglos XVI al XIX: Se denominaban Contadurías } \\
\text { mayores de los hechos o actividades públicos }\end{array}$ \\
\hline Gran Colombia & $\begin{array}{l}\text { Año 1822: Contaduría General de Hacienda } \\
\text { Año 1824: se elimina la Contaduría General de la } \\
\text { Hacienda y se crean las Contadurías }\end{array}$ \\
\hline
\end{tabular}




\begin{tabular}{|c|c|}
\hline & $\begin{array}{l}\text { Departamentales en Quito, Guayaquil y Cuenca. } \\
\text { Año 1826: Se reinstaura la Contaduría General } \\
\text { del Estado y los cargos de Contadores Generales y } \\
\text { contadores Departamentales. }\end{array}$ \\
\hline República del Ecuador & $\begin{array}{l}\text { Año 1830: se crean conjuntamente la Contaduría } \\
\text { General y las Contadurías Departamentales. } \\
\text { Año 1846: Se instituyeron las Contaduría } \\
\text { Mayores en las ciudades de Quito, Cuneca y } \\
\text { Guayaquil. } \\
\text { Año 1851: se estableció la Contaduría General } \\
\text { como Tribunal Superior de Cuentas y las } \\
\text { Contadurías Mayores como juzgados de distritos. } \\
\text { Año 1861: se crea el Tribunal de Cuentas } \\
\text { Año 1896: Se creó el Tribunal de Cuentas de } \\
\text { Guayaquil. } \\
\text { Año 1927: Se crea la Contraloría General de la } \\
\text { Nación (presidencia del lojano Isidro Ayora) } \\
\text { Año 1956: La Contraloría contaba ya con } 10 \\
\text { departamentos con un director a cargo. } \\
\text { Año 1967: Se modificó el nombre a "Contraloría } \\
\text { General del Estado" CGE } \\
\text { Año 1977: Se emitió la Ley Orgánica de } \\
\text { Administración financiera y Control, sustituyendo } \\
\text { a la Ley Orgánica de Hacienda } \\
\text { Año 2002: Se publica la Ley Orgánica de la } \\
\text { Contraloría General del estado en el suplemento } \\
\text { del Registro Oficial N.- 595, LEY N.- 2002-73 }\end{array}$ \\
\hline
\end{tabular}

\section{Recurso del Estado}

En su parte pertinente, en el Diccionario Jurídico (2005) (p.102), señala que: "los recursos del estado son los bienes cuya propiedad pertenece al Estado Nacional, a las provincias o a las 
municipalidades. Cuyo uso y goce, en la mayoría de los casos, está destinado a los particulares, como, por ejemplo, las calles, plazas, puentes". Es decir que ha sido adquirido con fondos públicos y por lo tanto su fin es contribuir a solucionar las necesidades de toda la población.

Por su parte la Ley Orgánica de la Contraloría General del Estado (Congreso Nacional, 2002) señala lo siguiente en su artículo 3: se entenderán por recursos públicos, todos los bienes, fondos, títulos, acciones, participaciones, activos, rentas, utilidades, excedentes, subvenciones y todos los derechos que pertenecen al Estado y a sus instituciones, sea cual fuere la fuente de la que procedan, inclusive los provenientes de préstamos, donaciones y entregas que, a cualquier otro título realicen a favor del Estado o de sus instituciones, personas naturales o jurídicas $\mathrm{u}$ organismos nacionales o internacionales. De ahí que el control riguroso que hace la CGE está por demás justificado con el fin de optimizar los recursos y minimizar los riesgos por mal uso de los mismos.

Los recursos del estado, son el instrumento que necesita una administración gubernamental para llevar a cabo su plan de trabajo; sin su existencia no sería posible que se logre solventar las problemáticas determinadas, y por lo tanto, no serviría la gestión emprendida por los representantes de la comunidad. Estos bienes y tributos deben ser guardados y maximizados con la mayor pertinencia, debido a que están destinados para un fin social y no lucrativo.

\section{Control}

Control es el término que se utiliza para determinar, en qué grado la administración de una entidad del estado ejerce sobre sus recursos, para que los mismos puedan ser utilizados de manera óptima. En relación a la CGE el control que realiza a las entidades del sector del estado, lo ejecuta a través de auditorías o exámenes especiales, siendo uno de los más comunes el relacionado con la auditoria forense, que a criterio de, se relaciona con el derecho y la aplicación de la ley, se la utiliza en un escenario real en el cual se ha presentado una considerable perdida financiera y se busca sus causas o causantes (Ocampo, Trejos Buriticá, \& Solarte Martínez, 2010). Los atributos que se requieren para ejercer este tipo de control son los siguientes.

La cuantificación de perdida financiera

Una comprensión de motivación 
Habilidades de comunicaciones, persuasión y una habilidad de comunicarse

Habilidades de mediación y negociación

Habilidades analíticas

Creatividad para adaptarse a nuevas situaciones

Otro enfoque de la auditoria es aquel mencionado en el trabajo de (Viloria, 2004), que menciona a Blanco, 1997 donde señala lo siguiente:

El proceso de obtener y evaluar objetivamente, en un período determinado, evidencia relativa a la información financiera, al comportamiento económico y al manejo de una entidad, con el propósito de informar sobre el grado de correspondencia entre aquellos y los criterios o indicadores establecidos o los comportamientos generalizados (p.89).

El control de los recursos públicos se lo ejecuta a través de diferentes formas y procedimientos, y es la CGE la que determina los motivos que conllevaron a que una dependencia publica sea objeto de llamado a brindar la información pertinente que se requiere para que un equipo especializado pueda realizar las indagaciones pertinentes para determinar responsabilidades que van desde lo administrativo hasta lo legal y penal, para sus directivos.

\section{Predeterminación de las Responsabilidades}

En función de las principales acciones emprendidas por la CGE, como organismo rector del control de los bienes públicos, propiciando su armonía con las necesidades de la población, estas son:

Tabla 1. Predeterminación de responsabilidades

\begin{tabular}{|c|c|c|c|c|c|c|c|c|c|c|}
\hline \multirow[t]{2}{*}{$\begin{array}{l}\text { UNIDAD DE } \\
\text { CONTROLL }\end{array}$} & \multicolumn{2}{|c|}{$\begin{array}{l}\text { RESPONSABILIDAD CIVIL } \\
\text { CULPOSA - GLOSA }\end{array}$} & \multicolumn{2}{|c|}{$\begin{array}{l}\text { RESPONSABILIDAD CIVIL } \\
\text { CULPOSA - ORDEN DE } \\
\text { REINTEGRO }\end{array}$} & \multicolumn{2}{|c|}{$\begin{array}{c}\text { RESPONSABILIDAD } \\
\text { ADMINISTRATIVA } \\
\text { CULPOSA }\end{array}$} & \multicolumn{2}{|c|}{$\begin{array}{c}\text { OTRAS } \\
\text { RESPONSABILIDADES } \\
\text { ADMINISTRATIVAS }\end{array}$} & \multicolumn{2}{|c|}{$\begin{array}{l}\text { TOTAL PREDERMINADAS } \\
\text { POR UNIDADES DE } \\
\text { CONTROL }\end{array}$} \\
\hline & $\mathrm{N}^{\circ}$ & MONTO & $\mathbf{N}^{\circ}$ & MONTO & $\mathbf{N}^{\circ}$ & MONTO & $\mathbf{N}^{\mathbf{o}}$ & MONTO & $\mathbf{N}^{\mathbf{o}}$ & MONTO \\
\hline TOTALES & 1005 & 1.107.644.331,35 & 220 & $41.417 .150,85$ & 7383 & $10.292 .921,00$ & 40 & $212.565,00$ & 8648 & $1.159 .566 .968,20$ \\
\hline
\end{tabular}

Fuente: Informe 2017 de la CGE 
Entre todas las unidades adscritas a la CGE se ha podido determinar un monto de $\$ 1.159 .566,20$ por responsabilidades en sus distintas modalidades, a través de exámenes especiales, teniendo los implicados la posibilidad de presentar todos los alegatos que se creyeran convenientes para demostrar que no han estado actuando al margen de la Ley y sus Reglamentos. De llegar a darse el caso de poder recuperar ese monto, el estado contaría con un valor significativo dentro de sus arcas fiscales para solventar las grandes necesidades en tiempos de austeridad.

Tabla 2. Entidades de control de la CGE en Loja

\begin{tabular}{|l|r|r|}
\hline \multicolumn{1}{|c|}{ SECTOR } & \multicolumn{1}{|c|}{$\mathbf{N}^{\mathbf{0}}$ ENTIDADES } & \multicolumn{1}{c|}{$\%$} \\
\hline DESARROLLO & 136 & $61,82 \%$ \\
SECCIONAL & 20 & $9,09 \%$ \\
\hline SALUD & 14 & $6,36 \%$ \\
\hline EDUCACIÓN & 50 & $22,73 \%$ \\
\hline OTRAS TOTAL & 220 & $100,00 \%$ \\
\hline
\end{tabular}

Fuente: Informe 2017 de la CGE

Al igual que en el resto del país, la provincia de Loja cuenta con un importante grupo de entidades gubernamentales, que, por operar con recursos públicos, deben ser sometidos a controles preventivos que contribuyen a mejorar sustancialmente su gestión en todas sus actividades. Específicamente las entidades de mayor incidencia en este control están en el componente o sector del Desarrollo Seccional que comprenden municipios y entidades adscritas a este tipo de entidades gubernamentales y que reflejan una salida importante de dividendos para su operatividad.

\section{Análisis políticos actuales:}

Con la terminación de 10 años del correato se ha procedido a determinar responsabilidades a importantes personalidades de este grupo político por parte de la CGE, destacando los siguientes:

Análisis de la adquisición de los helicópteros de procedencia india

Análisis del caso de secuestro político

Análisis del 30s

Análisis de obras públicas emblemáticas 
Análisis casos Odebrech

Y otros que, por su coyuntura con el anterior régimen, han sido considerados como prioritarios al tener la visión de la existencia de suficientes evidencias que demostrarían el mal uso de los recursos públicos.

\section{Conclusión}

El control de los recursos públicos por parte de la CGE es una medida que debe:

Fortalecerse por los casos de corrupción de algunos funcionarios que aprovecharon de su posición jerárquica para lucrar de manera personal.

Utilizar de manera oportuna las unidades adscritas a la CGE para todas las actividades en las cuales sean solicitadas.

\section{Referencias Bibliográficas}

Asamblea Nacional Constituyente. (2008). Constitución Política de la República del Ecuador.

Congreso Nacional. (2002). Ley Orgánica de la Contraloría General del Estado

Diccionario Jurídico (2005). República del Ecuador.

Ocampo, C. A., Trejos Buriticá, O. I., \& Solarte Martínez, G. R. (2010). LAS TÉCNICAS FORENSES Y LA AUDITORIA. Scientia Et Technica, vol. XVI, 109. Obtenido de http://www.redalyc.org/articulo.oa?id=84917249019

Viloria, N. (2004). Una aproximación a un enfoque holístico en auditoria. Actualidad Contable Faces, 89. Obtenido de http://www.redalyc.org/articulo.oa?id=25700909 